\title{
Observed aerosol-induced radiative effect on plant productivity in the eastern United States
}

\author{
S. Strada ${ }^{a, b, *}$, N. Unger ${ }^{a}$, X. Yue ${ }^{a}$ \\ ${ }^{a}$ Yale University, School of Forestry and Environmental Studies, 195 Prospect Street, 06511 \\ New Haven (CT), USA \\ 5 \\ ${ }^{b}$ Now at Laboratoire des Sciences du Climat et de l'Environnement, L'Orme des Merisiers - \\ Bat 712, 91191 Gif Sur Yvette FRANCE
}

\begin{abstract}
We apply satellite observations of aerosol optical depth (AOD) in conjunction with flux tower-derived estimates of gross primary productivity (GPP) to probe the relationship between atmospheric aerosol loading and carbon uptake rate at 10 select sites (4 deciduous broadleaf, 3 cropland, 1 evergreen needle leaf, 1 mixed forest and 1 grassland) on hourly time scales in the growing season in the eastern United States. For deciduous and mixed forests, the aerosol light scattering increases GPP with a maximum effect observed under polluted conditions $(\mathrm{AOD}>0.6)$, when diffuse radiation is $40-60 \%$. During midday hours, high AOD conditions $(>0.4)$ enhance plant productivity by $\sim 13 \%$ in deciduous forests. In contrast, we find that high diffuse light fraction does not increase the carbon uptake rate in croplands and grasslands; for these ecosystems, we estimate that high AOD conditions reduce GPP by 17\% during midday hours. Our findings are consistent with previous studies that have attributed these contrasting response sensitivities to the complex and closed canopy architecture of forests versus crops and grasslands. $\mathrm{C}_{4}$ but not $\mathrm{C}_{3}$ crops may benefit from pollution-induced changes in diffuse and direct light. Further research is needed to investigate the role of local meteorology as a possible confounder in the connection between atmospheric aerosols and plant productivity.
\end{abstract}

Keywords: Plant productivity, aerosols, diffuse light, eastern U.S.,

FLUXNET, MODIS 3-km AOD

${ }^{*}$ Corresponding author

PrepEintiduddditest tsuEdneaiestrada@lsce.ipsl.fr (S. Strada)

September 17, 2015 


\section{Introduction}

Using light energy, terrestrial vegetation accomplishes photosynthesis and fixes water and carbon dioxide $\left(\mathrm{CO}_{2}\right)$ in its living tissues. The $\mathrm{CO}_{2}$ uptake from the atmosphere by plants is defined as terrestrial gross primary productivity (GPP) and depends on temperature and the supplies of water, photosynthetically active radiation (PAR, spectral range of surface visible solar radiation, 400-700 nm, used by plants to photosynthesize) and nutrients (Beer et al., 2010; Kanniah et al., 2012). Surface solar radiation (SSR, the sum of the direct and diffuse radiation incident on the surface) is modified by atmospheric aerosols that absorb and scatter incoming solar beams (aerosol direct effect) (Ramanathan et al., 2001). Predominantly scattering aerosols (including sulfates, nitrates and organics) alter the partitioning between direct and diffuse radiation and increase the diffuse fraction (Wild, 2009). Absorbing aerosols such as black carbon may reduce SSR. For instance, stratospheric sulfate produced by the Mount Pinatubo eruption in 1991 substantially increased the diffuse radiation fraction. Considering cloudless conditions, Gu et al. (2003) assessed that this rise in diffuse light enhanced plant productivity in a deciduous forest by $23 \%$ and $8 \%$, respectively, in the two years following the volcanic eruption. This finding enforced the knowledge gained by ecologists from observational studies: plant productivity is more efficient under diffuse rather than direct light $(\mathrm{Gu}$ et al., 2002). Under high-light conditions, sunlit leaves saturate their photosynthetic rate (i.e., as a function of PAR), while shaded leaves have a lower radiation load and can increase their photosynthetic rate. Under low-light conditions, sunlit leaves remain light saturated, while shaded leaves may enhance their photosynthetic rate due to an increase in multi-directional diffuse light, which reduces the volume of shade within the vegetation canopy by more than an order of magnitude (Roderick et al., 2001). This response is named "diffuse fertilization effect" and has been observed under cloudy skies or chronic aerosol loading (e.g., Niyogi et al., 2004; Oliveira et al., 2007; Knohl and Baldocchi, 40 2008; Cirino et al., 2014; Cheng et al., 2015). 
Measurements of $\mathrm{CO}_{2}$ flux across the globe have suggested that the diffuse fertilization effect prevails in complex canopies with high leaf area index (LAI, defined as one-sided green leaf area per unit ground area, $\mathrm{m}^{2} \mathrm{~m}^{-2}$ ) and depends on plant functional type (PFT). Canopies whose architecture is closed 45 with clumped leaves (e.g., forests) respond positively to an increase in diffuse radiation (Cheng et al., 2015), while no or opposite effects are observed in open canopies (e.g., grasslands) (Niyogi et al., 2004). Canopy complexity also depends on LAI: a high LAI $\left(>2-3 \mathrm{~m}^{2} \mathrm{~m}^{-2}\right)$ implies a higher ratio of shaded to sunlit leaves, as well as a denser vegetation canopy (Letts et al., 2005; Alton 50 et al., 2007; Wohlfahrt et al., 2008). Canopy architecture, LAI and the adopted photosynthetic pathway $\left(\mathrm{C}_{3}\right.$ or $\left.\mathrm{C}_{4}\right)$ distinguish vegetation types. $\mathrm{C}_{3}$ and $\mathrm{C}_{4}$ photosynthetic pathways differ in light-use efficiency (LUE, which can be defined as the ratio of GPP to PAR). $\mathrm{C}_{4}$ PFTs are adapted to high light and warm climates and do not become light saturated under most natural conditions, due to a reduced rate of photorespiration; hence, they may respond in a different way to a change in diffuse radiation compared to $\mathrm{C}_{3}$ PFTs (Greenwald et al., 2006; Kanniah et al., 2012; Cheng et al., 2015). Cited differences between vegetation types (canopy architecture and PFTs) result in a wide range of optimum diffuse fraction values that enhance plant productivity: in forested ecosystems 60 optimum diffuse fraction spans from $40 \%$ to $80 \%$ (Hollinger et al., 1994; Rocha et al., 2004; Knohl and Baldocchi, 2008).

Aerosol-induced effects on photosynthesis depend on the atmospheric aerosol loading. Aerosol optical depth (AOD) is a dimensionless measure of the atmospheric transparency (high AOD indicates low transparency). Intermediate AOD values enhance plant productivity; in the Amazon Basin region, Oliveira et al. (2007) pinpointed 1.6-1.7 as optimum AOD values. On the contrary, high AODs (> 2-3) have the opposite effects on carbon uptake rate (Oliveira et al., 2007; Artaxo et al., 2013; Cirino et al., 2014). Under such high AODs, the reduction in direct radiation is large enough to counteract the diffuse fertilization 70 effect (Kanniah et al., 2012).

In the U.S., SSR has undergone dramatic increases in the past two decades. 
Between 1995 and 2007, U.S. SSR increased by $10 \mathrm{~W} \mathrm{~m}^{-2}$ decade $^{-1}$ (Wild, 2009, 2012). This brightening trend has been linked to the regional reduction in AOD, especially from anthropogenic sulfate due to sulphur dioxide $\mathrm{SO}_{2}$ emission reduction measures under the Clean Air Act Amendements (1990) (Wild et al., 2009). Based on improved regional emission inventories, Streets et al. (2009) estimated an annual average decline in AOD of $2.1 \%$ over the period 1980-2006; this trend was confirmed by long-term observations of sulfate concentrations over the period 1992-2010, with a larger decline in the eastern U.S. (Hand et al., 2012). The substantial recent reduction in the aerosol loading over the eastern U.S. necessitates a re-assessment of the diffuse fertilization effect in this region, which has not been analyzed after a decade since the study of Niyogi et al. (2004). Furthermore, the eastern U.S. represents an important case study for the "diffuse fertilization effect" because this region has a large light-scattering potential due to production of biogenic secondary organic aerosols (BSOA) as highlighted by Carlton et al. (2010). At the same time, the newly released MODIS Collection 6 now provides clear-sky AOD at $3 \mathrm{~km}$ resolution that offers better characterization of the local aerosol loading (Levy et al., 2013; Remer et al., 2013; Munchak et al., 2013). In the present study, we take advantage of this newly released MODIS AOD product in conjunction with quasi-coincident GPP estimates derived from the AmeriFlux network to probe the aerosol-induced radiative effect on plant productivity over the eastern U.S. on hourly time scales. The major goals of this work are: (1) to quantify the relationship between aerosol loading and plant productivity across different vegetation types; (2) to re-assess the role of diffuse and direct light in the aerosol-photosynthesis relationship in a region that underwent a recent large reduction in aerosol pollution; and (3) to estimate the change in plant productivity under high versus low AOD conditions. In our analysis, we account for the changes in ambient conditions (e.g., temperature and water availability), however we do not disentangle indirect thermal effects that may accompany the diffuse fertilization effect. Compared to the study of Niyogi et al. (2004), beyond using high-resolution MODIS AOD product, we analyzed ten AmeriFlux 
sites (instead of six) over mainly five-ten years of observations (instead of twofour years), including evergreen needle leaf among targeted vegetation types; furthermore, where and when available, we applied diffuse PAR observations.

Section 2 introduces the observational datasets used in the present study, and describes the data analysis methodology. In Section 3, results are presented and discussed. Conclusions are summarized in Section 4.

\section{Data and methodology}

We computed the linear correlation between the quasi-coincident high-resolution MODIS AOD and AmeriFlux data (GPP and diffuse/direct PAR), both collected during the growing season in the eastern U.S. (June-August) (Sect. 2.12.3). By applying multiple linear regression, we ranked the effect of ambient conditions on GPP when aerosols are observed (Sect. 2.4). We also quantified the percentage change in GPP under high and low AOD conditions (Sect. 2.5).

\subsection{MODIS Aerosol Optical Depth at high resolution}

MODIS provides AOD at 550-nm wavelengths, where aerosols may interfere with PAR. In this study, we used the Quality Assured Aqua MODIS aerosol product with 3-km resolution from Level 2 Collection 6 (hereafter MODIS Aqua L2 C6 3-km AOD) over the period 2003-2013.

Recently released MODIS C6 includes substantive adjustments compared to the previous collection (e.g., updated cloud mask to retrieve heavy smoke, improved quality assurance, spatially refined aerosol type map) (Levy et al., 2013). The MODIS 3-km AOD product results from the "dark target" retrieval algorithm, which is designed to infer clear-sky (non cloudy) aerosol properties in the visible spectrum over surfaces with low reflectivity (e.g., ocean, vegetation) (Levy et al., 2010). Compared to the standard 10-km algorithm, the $3-\mathrm{km}$ algorithm differs in the number of pixels required to accomplish a retrieval after all masking and filtering are applied (e.g. cloud, snow and ice, too-bright surfaces); at most, 11 (120) pixels are needed in the $3-\mathrm{km}(10-\mathrm{km})$ algorithm 
(Remer et al., 2013). Global 3-km AOD was thoroughly validated against sun photometers with a lower performance compared to 10-km AOD: $63 \%$ of global collocations fell within the expected error over land compared to $69 \%$ for the 10 km AOD (Remer et al., 2013). Munchak et al. (2013) compared the performance of the 3 - and 10-km products at a urban/suburban scale (Baltimore-Washington DC, USA) during summer 2011. The authors highlighted strengths (e.g., ability to retrieve closer to clouds and coastlines) and weaknesses (e.g., more susceptible to cloud contamination or other sources of noise) of the $3-\mathrm{km}$ product and pointed out poor performance of the $3-\mathrm{km}$ product over urban surfaces, due to improper characterization of reflectance at urban sites. We acknowledge the limits of the MODIS 3-km AOD product; however, because AmeriFlux sites are located far away from urban sites and represent dark regions (except for croplands), this new product may better characterize the aerosol loading at AmeriFlux sites, and this potential needs to be explored.

\subsection{FLUXNET-AmeriFlux data: Plant productivity and diffuse light}

Plant productivity (GPP) cannot be measured directly; therefore, GPP is estimated as the difference between the daytime total ecosystem respiration (Reco) and the daytime Net Ecosystem $\mathrm{CO}_{2}$ Exchange (NEE) (Schaefer et al., 2012). Direct measures of NEE are provided by the eddy covariance method, a micrometeorological technique that measures $\mathrm{CO}_{2}$, water vapor and energy fluxes over short and long timescales and samples a relatively large area (range of length scales: 100-2000 m) (Baldocchi et al., 2001). The eddy covariance method was adopted in the 90s' by AmeriFlux (AMF), which is the North American network of the global network of micrometeorological flux measurement tower sites (FLUXNET, http://fluxnet.ornl.gov/).

The AMF network offers a large diversity in terms of biomes and climates studied (http://ameriflux.ornl.gov). We selected a subset of AMF sites that: (1) are located in the eastern U.S. (longitude range: $70^{\circ}-110^{\circ} \mathrm{W}$ ) to reduce the impact of water stress on plant productivity; (2) provide at least 5 years of measurements that overlap the observing period of the MODIS- 
Aqua sensor (2003-2013); and (3) represent different vegetation types. We used half-hourly/hourly non-gap-filled daytime GPP and, where available, PAR and diffuse PAR during summer (June-August). This period corresponds to the growing season, when photosynthetic activity and canopy capacity peak (Niyogi et al., 2004). The final selection counts ten AMF sites that cover five vegetation types: 4 deciduous broadleaf forests, 3 croplands, 1 evergreen needleleaf forest, 1 mixed forest, and 1 grassland (Table 1 and Fig. 1). The Bondville and Walker Branch AMF sites were additionally selected to validate sampled MODIS AOD using AERONET observations available there (see Sect. 2.3).

The eddy covariance method works well under strict conditions (e.g., flat terrain, steady atmosphere, large vegetated area) that are rarely met at AmeriFluxFLUXNET sites. The so-called energy balance closure problem (i.e., available energy is larger than turbulent heat fluxes) is observed when the eddy covariance method is used and could imply an underestimation of $\mathrm{CO}_{2}$ flux; however, it is uncertain to what extent the lack of energy balance closure may affect observed GPP (Foken, 2008; Baldocchi, 2008).

\subsection{Correlation of plant productivity, diffuse light and aerosol loading}

To investigate the linear relationship between aerosol loading, plant productivity and diffuse/direct light, our methodology is based on three steps:

1. Sample MODIS AOD over AMF sites during summer.

Depending on the location and meteorological conditions (e.g., cloudy days), MODIS Aqua retrieves approximately 2 AOD pixels between 10:00 and 14:00 Local Time (LT) daily. Using instantaneous MODIS Aqua L2 C6 AOD pixels at $3 \mathrm{~km}$, for each summer day we selected all MODIS AOD pixels that are located within a distance of $0.03^{\circ}(\sim 3 \mathrm{~km})$ from the target AMF site. Cloud mask, applied in the MODIS retrieval procedure, conveniently filters out cloudy days and should reduce the effect of clouds in the scattering process.

2. Validate AOD sampling using ground-based AERONET observations. 
To validate our sampling technique and to corroborate the potential of the MODIS 3-km AOD product, we compared sampled MODIS AOD with ground-based AOD collected from AERONET. We used AERONET Version 2 Level 2 "all points" data (quality assured and cloud free, AERONET v2.0). To compute the linear correlation Pearson's coefficient (hereafter Pearson's R) between MODIS 3-km AOD and AERONET v2.0 AOD, we selected AERONET data within a time span of 30 minutes from the selected MODIS 3-km AOD (both MODIS and AERONET data are in UTC time). AERONET database provide AOD observations at a higher daily frequence (multiple times per hour) compared to MODIS ( $\sim 2 \mathrm{AOD}$ pixels per day). To avoid comparing multiple AERONET values with a single MODIS value available at a specific scan time, we computed the arithmetic average of multiple AERONET values matching MODIS scan time.

Among selected FLUXNET sites, four provide AERONET observations of AOD at $500 \mathrm{~nm}$ for portions of 2003-2013: Bondville, Harvard Forest, Howland Forest, and Walker Branch.

Very few AERONET stations have a 550-nm channel; therefore, we used 500-nm AOD. We do not expect 550- and 500-nm AOD to perfectly agree; however, MODIS C6 3-km AOD significantly correlates with AERONET AOD $(R>0.9)$ with regression slopes ranging from 0.9 to 1 (Fig. 2$)$. In general, MODIS 3-km AOD is biased (high and low); however, we verified slight improvements in MODIS-AERONET correlation moving from C5 to C6 (Levy et al., 2013), as well from C6 10-km AOD to 3-km AOD (not shown).

The MODIS-AERONET comparison validates our sampling technique of AOD values at AMF sites as well as our choice of the 3-km AOD product; hence, our study should be comparable to studies based on ground-based observations (e.g., Niyogi et al., 2004; Oliveira et al., 2007) and those based on the MODIS 10-km AOD product (Steiner et al., 2013; Cirino et al., 2014). The MODIS 3-km AOD bias may affect our ability to study 
the response of plant productivity under polluted conditions. We consider, though, that MODIS is a more suitable platform to investigate the aerosol direct effect and the associated radiative effect on plant productivity since it provides information along the entire atmospheric column, being able to observe local as well as transported pollution. For example, high AODs were observed at high altitudes over the eastern U.S. and were attributed to wildfires in the western U.S. (Munchak et al., 2013).

At the time of analysis, MODIS C6 was available only for the Aqua satellite; this constraint may reduce the number of AOD retrievals available at AMF sites. Figure 3 shows the MODIS AOD time series at the ten selected AMF sites during summer days for years when AMF observations are also available. Overall the ten sites have $\sim 100-300$ AOD retrievals over the entire number of years. Except for the UMBS site, which exhibits a poor number of high AOD retrievals, the number of days with $\mathrm{AOD}>0.3(\mathrm{AOD}<0.2$ is considered fairly clean $)$ is around 10-30; all sites show conditions normally associated with pollution ( $\mathrm{AD}>0.6$ ), while a few sites show conditions normally associated with smoke events $(\mathrm{AOD}>1.5)$. Our number of AOD retrievals is reasonable compared to the study of Steiner et al. (2013), where both MODIS C5 Terra and Aqua 10-km AOD were used.

3. Select quasi-coincident AMF and MODIS observations.

We selected AMF observations (GPP, total and diffuse PAR, surface atmospheric temperature, vapor pressure deficit and precipitation) collected between 10:00 and 14:00 LT. The chosen midday window overlaps with MODIS transit; moreover, it removes the early morning and late afternoon periods when confounding factors, such as low solar angles or high diffuse fraction, may affect the amount of diffuse light and influence plant productivity (Niyogi et al., 2004). Negative GPP was considered as a missing value. To reduce the influence of cloud cover, we filtered out instants (both AMF and MODIS observation) when precipitation was not zero. 
Finally, we computed Pearson's $R$ coefficients between AOD and GPP at all selected AMF sites. At AMF sites where PAR and diffuse PAR are measured, we calculated direct PAR as the difference between PAR and diffuse PAR and computed Pearson's $R$ between diffuse/direct PAR and MODIS AOD and between diffuse PAR and GPP. To ensure the robustness of our analysis, we impose a $\mathrm{p}$ value $<0.05$ in all correlation analysis. Days when either AMF observations or MODIS AOD were absent are not used in this study.

As Steiner et al. (2013), we correlated instantaneous values for MODIS AOD and AMF observations. However, there is unavoidable uncertainty due to temporal differences between MODIS and FLUXNET data availability, which explains our definition of "quasi-coincident" AMF and MODIS data.

\subsection{Rank the impact of ambient conditions on GPP}

Plant productivity is tightly linked to ambient conditions such as the supply of light, temperature and water availability. By modifying ambient conditions (beyond diffuse light), aerosol pollution affects plant productivity. To account for the role of ambient conditions on plant productivity under pollution aerosols, at AMF sites that provide diffuse PAR we perform multiple linear regression (MLR) using AMF data quasi-coincident with MODIS AOD observations. In the MLR, the dependent variable is GPP. Independent variables are surface atmospheric temperature (SAT), diffuse and direct PAR and vapor pressure deficit (VPD):

$$
G P P=\beta_{0}+\beta_{1} S A T+\beta_{2} P A R_{d i f}+\beta_{3} P A R_{d i r}+\beta_{4} V P D+\epsilon
$$

In the above formula, $\epsilon$ is the error term, while $\beta$ are the standardized regression coefficients that represent the partial regression coefficients in units of standard deviation. When standardized regression coefficients are statistically significant (p-value $<0.05$ ), they can be compared directly. Hence, although MLR does not account for tight connections existing between independent variables (e.g., light affects temperature), it enables ranking of the ambient conditions that have the strongest influences on GPP at AMF sites. 
To quantify the effect of different AOD levels (high vs. low) on diurnal plant productivity, we binned hourly/half-hourly daytime GPP estimates (6:00-18:00 LT) into high $\mathrm{AOD}(>0.4)$ and low AOD $(<0.3)$ days (i.e., daily mean of instantenous MODIS C6 3-km AOD). Afterwards, we averaged all values to obtain two mean GPP diurnal cycles: under high AOD and low AOD conditions. The percentage change between GPP diurnal cycle under high and low AOD was calculated accounting for midday hours (10:00-14:00 LT) in each GPP diurnal cycle. A Student's $t$ test with a $95 \%$ confidence interval $(p<0.05)$ assessed the statistical significance of the percentage change.

AOD values between 0.3 and 0.4 were excluded to limit the overlap between high and low AOD conditions. To ensure a fair number of retrievals under high-AOD conditions, we fixed a less stringent high-AOD threshold compared to Steiner et al. (2013) (0.4 vs. 0.5). As already pointed out by Steiner et al. (2013), the binning procedure provides a method to quantify the effect of different AOD levels on plant productivity; however, it may combine effects on GPP daily cycle that are not related to AOD conditions (e.g., clouds or instrument error).

\section{Results and discussion}

Atmospheric aerosols considerably modify light supply and its partitioning at the surface (Sect. 3.1). The change in light partitioning and the increase in diffuse light (through scattering) affect plant productivity in complex canopies (Sect. 3.2). Furthermore, high AOD levels seem to influence the GPP diurnal cycle, with robust but opposite effects during midday hours for forests and croplands (Sect. 3.3).

\subsection{Impact of aerosols on diffuse and direct light}

Aerosols directly affect the quality of light by increasing the diffuse fraction (scattering) and decreasing the direct fraction (scattering and absorption). Six of the selected AMF sites provide ground-based measurements of total and 
diffuse PAR, which permits quantification of direct PAR (total PAR minus diffuse PAR). Figure 4 shows the linear relationship between diffuse/direct PAR and AOD values at 4 sites, out of the 6 that collect both PAR and diffuse PAR. Direct PAR is not directly measured and presents a large variability at low $\operatorname{AOD}(<0.6)$, which may be introduced by our calculation. At Morgan Monroe, we discarded year 2008 because diffuse PAR showed large values ( $\left.900 \mu \mathrm{mol} \mathrm{m}{ }^{-2} \mathrm{~s}^{-1}\right)$ at AOD lower than 0.4. At all sites, diffuse PAR increases linearly with AOD values (mean $R=0.9$ ), while direct PAR decreases (mean $R=-0.7$ ). Except for the UMBS site (poor number of AOD retrievals, Fig. 3), the linear relationship between diffuse/direct PAR and the aerosol loading is robust (Table 2 ).

Our results are consistent with previous observational studies that pointed out the robust linear relationship between aerosol loading and the supply and quality (direct vs. diffuse) of light at the surface (Oliveira et al., 2007; Steiner et al., 2013; Cirino et al., 2014). We conclude that: (1) MODIS AOD is a reliable proxy for diffuse light and (2) AOD and diffuse (direct) light are positively (negatively) correlated at observed AOD levels $(<1.8)$. In the next section, we investigate the impact of AOD on plant productivity, and we further explore the relationship between plant productivity, AOD levels and diffuse fraction.

\subsection{Plant productivity versus aerosol optical depth}

Due to the effect of both clouds and aerosols, the increase in diffuse light enhances plant productivity and explains 5-20\% of the change in GPP at sites characterized by a complex and closed canopy, such as deciduous (Morgan Monroe and UMBS) and evergreen (Howland) forests (mean $R=0.4$, mean $R^{2}=0.2$, Table 2). At croplands, we observe no correlation between diffuse PAR and GPP (Table 2). These results are in accord with the study of Cheng et al. (2015) that separates and quantifies the effect of diffuse light on GPP using data from the same AMF sites (Morgan Monroe, UMBS, Howland and Mead). Considering data collected around 10:00-14:00 LT, the authors estimate that diffuse PAR explains $13-17 \%$ of variations in GPP at forest sites, while no (or 
slight) correlation is observed at croplands (Fig. 1 in Cheng et al., 2015). The Konza Prairie site seems to confirm that aerosols do not affect plant productivity in grasslands (Niyogi et al., 2004). However, at Konza Prairie conditions are fairly clean over the observed period (only 17 AOD values $>0.3$ over 20072009). Moreover, grassland response may depend on LAIs. Under increasing diffuse light, Wohlfahrt et al. (2008) documented an enhancement of $35 \%$ in NEE over grasslands at high LAI $\left(4-6 \mathrm{~m}^{2} \mathrm{~m}^{-2}\right)$, while NEE was not sensitive at low $\left(<2 \mathrm{~m}^{2} \mathrm{~m}^{-2}\right)$ and intermediate LAI $\left(2-4 \mathrm{~m}^{2} \mathrm{~m}^{-2}\right.$, signal not statistically significant). At Konza Prairie, LAI show a wide range $\left(2.5-6.3 \mathrm{~m}^{2} \mathrm{~m}^{-2}\right.$, Table 1); however, LAI evolution is not provided coincident with GPP.

Figure 5 shows the linear relationship between GPP and diffuse PAR (clouds and aerosol effects) and GPP-AOD at forest sites that provide diffuse PAR (Morgan Monroe and Howland Forest). At Morgan Monroe, plant productivity positively correlates with both diffuse PAR and AOD (Fig. 5a-b). Under polluted conditions (AOD > 0.6), diffuse fraction is 40-60\% (diffuse PAR $600-1000 \mu \mathrm{mol} \mathrm{m}{ }^{-2} \mathrm{~s}^{-1}$ ) and is associated with high plant productivity (mean GPP $\sim 30 \mu \mathrm{mol} \mathrm{m}{ }^{-2} \mathrm{~s}^{-1}$ ), while the opposite behavior is observed for the direct fraction (low AOD, high direct fraction and low GPP) (not shown). Our value matches the estimated optimum range of diffuse fraction that enhances GPP in deciduous broadleaf forests: 40-80\% (Rocha et al., 2004; Alton et al., 2007; Knohl and Baldocchi, 2008). At Howland Forest, plant productivity shows a robust positive correlation with diffuse PAR, while remaining constant when AOD increases (Fig. 5c vs. 5d). This contrasting behavior might depend on AOD observations; compared to Morgan Monroe, half AOD retrievals are available and half polluted conditions (AOD > 0.3) occur at Howland Forest (Fig. 3b vs. $3 \mathrm{~d})$. The literature reports contrasting results regarding plant productivity and diffuse light in needle leaf forests. Alton et al. (2005) observed a slight enhancement $(<10 \%)$ in carbon assimilation under diffuse light conditions compared to direct light during two growing seasons in a Siberian pine forest, while $\mathrm{Gu}$ et al. (2002) report an increase in LUE at a Scots pine forest (Finland).

At cropland sites, the range in plant productivity is twice that of decidu- 
ous and evergreen forests. Under a varying aerosol loading, $\mathrm{C}_{4}$ (maize) and $\mathrm{C}_{3}$

(soybean) crops distinguish in their GPP-diffuse PAR relationship. While at $\mathrm{C}_{3}$ crops, aerosol instants scatter over the whole range of GPP values $\left(0-40 \mu \mathrm{mol} \mathrm{m}^{-2} \mathrm{~s}^{-1}\right)$; at $\mathrm{C}_{4}$ crops, aerosol instants are associated with high GPP (above $40 \mu \mathrm{mol} \mathrm{m}^{-2} \mathrm{~s}^{-1}$ ) (blue dots in Fig. 6). We focus on midday hours since confounding factors (i.e., low solar angle, high diffuse fraction) may overlap the possible aerosol effect in the early mornings and late afternoons. The study of Cheng et al. (2015) analyzes the GPP-diffuse PAR relationship at different zenith angles (from early morning to late afternoon). The authors show that cropland productivity benefits from high diffuse light at large zenith angles (early mornings and late afternoons). As explained by Cheng et al. (2015), crop canopy architecture is designed to optimize LUE when the sun is overhead (minimum leaf self-shading); hence, self-scattering is reduced in croplands and their plant productivity depends mainly on incident (diffuse/direct) light. At midday hours (small zenith angles), we observe that, due to aerosols, incident direct (diffuse) light significantly decreases (increases) (Fig. 4e-h). The reduction in incident direct light may play the main role and limit plant productivity in croplands more efficiently than the observed increase in incident diffuse light. At the Mead sites, AOD values around 1.2-1.5 are observed at the beginning and at mid-summer and correspond to low GPP values $\left(\sim 0-20 \mu \mathrm{mol} \mathrm{m}{ }^{-2} \mathrm{~s}^{-1}\right)$; such high AOD levels might be associated with smoky/highly polluted conditions and may indicate a negative impact of anthropogenic aerosol pollution on the "corn belt" (Fig. 3e-g and Fig. 6c, 6e and 6g). In a more complex canopy, such as the Amazon tropical rainforest, similar AOD values (1.6-1.7) were identified as optimum AODs that maximize NEE (Oliveira et al., 2007). This finding highlights the different responses among PFTs to a change in the aerosol loading and, consequently, in diffuse light and suggests the importance of exploring the aerosol-photosynthesis relationship in the context of land-use change studies (e.g., from forests to croplands).

Among sites where diffuse PAR is not measured, Park Falls (mixed forest) and Harvard Forest (deciduous) show positive correlations between GPP and 
AOD, however the signal is not robust (Fig. 7a-b), probably because of a weaker occurrence of polluted conditions (AOD > 0.3) compared to Morgan Monroe. At Park Falls a few highly polluted conditions occur $(\mathrm{AOD}>1.2)$, however the number of polluted conditions is half that observed at Morgan Monroe (Fig. 3a vs. 3d). At Harvard Forest, more polluted conditions occurred compared to Park Falls, however AOD values are lower than 0.8 more (Fig. 3h vs. 3d). At Willow Creek, we do not observe any relationship between GPP and AOD; although a few highly polluted conditions occurred at this site, they do not overlap with GPP estimates, which may limit our result.

To summarize, consistent with the study of Niyogi et al. (2004) over the U.S., our findings show that around midday hours, aerosol light scattering favors plant productivity in a complex, closed canopy with high LAI (forest with mean canopy height $\sim 24 \mathrm{~m}$ and $\mathrm{LAI} \simeq 4 \mathrm{~m}^{2} \mathrm{~m}^{-2}$ ), while it does not provide benefits to open canopies such as grasslands (canopy height $0.4 \mathrm{~m}$ ), although the limited number of AOD retrievals influence the significance level at certain sites. In contrast with Niyogi et al. (2004), we do not observe any specific relationship between high aerosol loadings (high diffuse light) and plant productivity in croplands. Using an established modeling framework and performing sensitivity experiments, Matsui et al. (2008) showed that the aerosol light scattering has a negative or negligible impact on plant productivity over croplands. The authors concluded that croplands are more sensitive to an aerosol-cloud-driven reduction in direct light. This conclusion supports the hypotheses that cropland behavior may depend on other ambient conditions, beyond diffuse light, that aerosol pollution modified. Below, we explore further the relationship between plant productivity and ambient conditions under pollution aerosols and the different response of $\mathrm{C}_{4}$ and $\mathrm{C}_{3}$ crops.

\subsubsection{Dominant ambient conditions affecting GPP under aerosol pollution}

Under cloudless conditions (i.e., when MODIS AOD values are available), pollution aerosols modify ambient conditions such as direct and diffuse light, temperature and water stress. Change in ambient conditions finally affects 
plant productivity (Table 3 ).

When aerosols loading is detected, at AMF sites where diffuse PAR is measured, water stress (i.e., VPD) negatively affects GPP at all sites. If water vapor pressure deficit (VPD) increases, the relative humidity at the leaf surface decreases; as a result, canopy conductance, which is directly proportional to the relative humidity at the leaf surface and photosynthesis rate, decreases. The negative dependence of GPP on VPD may suggest that observed aerosol levels are not enough to reduce the water stress (hence to decrease VPD) and to provide benefits to plants by controlling canopy conductance. However, at sites where pollution aerosols enhance plant productivity (e.g., Morgan Monroe), the enhancement in plant productivity may prevail on the decrease in VPD and finally increase canopy conductance and evapotranspiration as shown by the modeling study by Steiner and Chameides (2005). Rise in evapotranspiration rates has the potential to finally affect hygroscopic aerosol production, which increase in size as the relative humidity increase, highlighting the tight connection between aerosols, vegetation and meteorology.

At Morgan Monroe, diffuse PAR confirms to play a dominant role and a positive impact on GPP. In contrast, at Howland Forest only VPD affects GPP. Recently, at Howland forest, Cheng et al. (2015) found evidence for the main contribution of VPD and air temperature to variations in GPP; in contrast, at Morgan Monroe, the authors mainly attribute variations in GPP to diffuse light, with VPD and temperature playing minor roles. At Morgan Monroe we observed higher temperature and water stress compared to Howland Forest. Hence, we hypothesize that at Morgan Monroe diffuse light restrains the limiting effect on GPP of high temperature and water stress.

At croplands, the response of GPP to ambient conditions do not distinguish between irrigated or rainfed conditions; this result may suggest that the aerosol loading reduces water stress at rainfed crops, assimilating their behavior to irrigated crops. On the contrary, we observe a different response of GPP to ambient conditions in $\mathrm{C}_{4}$ and $\mathrm{C}_{3}$ crops. At $\mathrm{C}_{4}$ crops (maize), surface temperature (SAT) 
of VPD; although playing a minor role (lower $\beta$ coefficient), both diffuse and direct PAR positively affects GPP. On the contrary, at $\mathrm{C}_{3}$ crops (soybean) both diffuse and direct PAR negatively affects GPP and enforces VPD impact. Concerning the effect of diffuse PAR on $\mathrm{C}_{4}$ vs. $\mathrm{C}_{3}$ crops, we conclude that diffuse PAR has a positive effect on $\mathrm{C}_{4}$ crops. In agreement, at the same AMF sites, Cheng et al. (2015) estimated a greater increase in GPP with diffuse light in $\mathrm{C}_{4}$ crops (maize) vs. $\mathrm{C}_{3}$ crops (soy). Compared to the $\mathrm{C}_{3}$ photosynthetic pathway, the $\mathrm{C}_{4}$ photosynthetic pathway is better adapted to high light and warm climates since, due to a higher light saturation point, it does not become light saturated under most natural conditions (Greenwald et al., 2006; Kanniah et al., 2012; Cheng et al., 2015). Hence, under increasing light conditions, $\mathrm{C}_{3}$ crops become light-saturated more rapidly than $\mathrm{C}_{4}$ crops and seem to not beneficiate from a change in light quantity and quality (i.e., more diffuse light, less direct light).

\subsection{Change in GPP diurnal cycle under high vs. low AOD conditions}

To further analyze the aerosol-induced effect on plant productivity, we compared the GPP diurnal cycle (6:00-18:00 LT) under high AOD (>0.4) versus low AOD $(<0.3)$ conditions at nine sites (UMBS was not considered due to the low number of AOD observations) (Fig. 8). At croplands $\mathrm{C}_{4}$ and grasslands, GPP diurnal cycle under high AOD (red line) shows a high variability (light red area) due to extremely low GPP observed under high AOD (1.2-1.5). This high variability may be caused by a single but extremely low GPP value that stretches the foot-print of the whole distribution. Visually, we notice that: (1) high AOD conditions correspond to higher GPP at forest sites, while high AOD conditions reduce GPP at grasslands and croplands (Fig. 8a-b and $8 \mathrm{~d}-\mathrm{f}$ vs. Fig. $8 \mathrm{c}$ and $\mathrm{g}-\mathrm{f}$ ) and (2) at forest sites, aerosol effect on GPP dominates around midday hours (Fig. 8a-b and 8d-f). In the morning and late afternoon available PAR is low and, therefore, plant productivity is light-limited in both sunlit and shaded leaves, as demonstrated by the modeling study of Matsui et al. (2008), especially in forest ecosystems because of a denser canopy. 
To quantify the impact of aerosols on plant productivity during midday hours (10:00-14:00 LT), we computed the percentage difference between GPP under high and low AOD (Table 4). Results show that high AOD conditions enhance plant productivity at forest sites (positive difference) with a robust increase of $\sim 13 \%$ observed at the Morgan Monroe (MMS) and Willow Creek (WCr) sites, both deciduous broadleaf forests. At Willow Creek, the analysis of the whole GPP diurnal cycle allows to account for the effect of high polluted conditions $($ AOD $>1.2)$ observed at this site and that do not overlay with GPP estimates. In contrast with results at forest sites, high AOD levels reduce plant productivity at grasslands and croplands, with a robust decrease of $\sim 17 \%$ at the Konza Prairie (Kon) and the Mead-Irrigated maize (Ne1). At Mead-Irrigated soybean (Ne2-C3), the robustness of the observed percentage difference between GPP under high and low AOD is limited (value in italics in Table 4) since a single high-AOD condition was observed over the whole period $(\mathrm{AOD}=1.2 \mathrm{in}$ 2006). By estimating the GPP-diffuse PAR relationship and its dependence on the zenith angle, Cheng et al. (2015) provide evidence that plant productivity benefits more from diffuse light (a) around midday hours at forest sites and (b) in early mornings and late afternoons at crop sites. The authors attribute the opposite behavior between forests and croplands to a different canopy architecture: compared to crops, forests have a higher canopy height and a more stratified structure that favor the use of diffuse light by the whole canopy when the sun is overhead.

We conclude that a thick aerosol loading increases the amplitude of the GPP diurnal cycle in a forest ecosystem, while it negatively affects plant productivity at grasslands and croplands, with a marked signal around midday hours (positive at forests, negative at grasslands and croplands). However, these results should be carefully interpreted. Even if we used MODIS AOD retrievals (cloud free) and we excluded observations when precipitation occurred, clouds can be present during the daytime and can efficiently scatter light; therefore, the assessed increase/decrease in GPP can not be completely ascribed to a thick aerosol loading. For example, in their modeling study, Greenwald et al. (2006) 
linked the aerosol-radiative effect on plant productivity at croplands with the occurrence of overcast vs. sunny days: aerosols have a more negative effect on crop productivity on cloudy days.

\section{Conclusions}

We used quasi-coincident high-resolution MODIS AOD and AmeriFlux data (GPP and diffuse/direct PAR) to assess the aerosol-induced radiative effect on plant productivity during the growing season in the eastern U.S. Our study complement the findings in Niyogi et al. (2004) and recent in Cheng et al. (2015); these studies investigated, respectively, the aerosol ligh-scattering effect on plant productivity and the overall relationship between diffuse light and GPP in the eastern U.S.

We acknowledge two main limitations in our study. Even if we used MODIS cloud-free retrievals, cloud effects may be present in both our correlation and diurnal cycle analyses and affect results, since clouds efficiently scatter light. In the present study, we discussed aerosol-induced effects on ambient conditions that finally affect plant productivity (e.g., change in surface temperatures and VPD) However, these thermal effects may also be related to the confounding role of meteorology in the aerosol-photosynthesis relationship (e.g., aerosols may affect evapotranspiration with consequences on aerosol production). Both aerosols and vegetation are tightly connected to meteorology; moreover, vegetation contributes to the aerosol loading through the formation of biogenic secondary organic aerosols (BSOA) (Hallquist et al., 2009). Therefore, in future studies, we aim to explore the aerosol-vegetation-meteorology system as a whole in order to disentangle the role of different drivers (e.g., light, temperature, humidity, aerosols, and soil moisture).

Despite these limitations, we showed in this study that increasing diffuse light enhances plant productivity in a complex and closed canopy around midday hours. In deciduous and mixed forests, aerosol loading and plant productivity are positively correlated. At Morgan Monroe (deciduous), high plant produc- 
tivity is associated with a medium diffuse fraction (40-60\%), observed under polluted conditions $(\mathrm{AOD}>0.6)$. Among selected AMF sites, only at Morgan Monroe the positive relationship between GPP and diffuse PAR is robust. This result may depend on (a) the limited number of AOD retrievals (only MODIS AQUA C6 was available at the time of the study) or (b) the reduced number of polluted conditions in the eastern U.S..

By analyzing ambient conditions that co-vary under pollution aerosols (diffuse/direct light, temperature and water stress), we distinguish the response of GPP to light variation (diffuse vs. direct light) in $\mathrm{C}_{4}$ (maize) and $\mathrm{C}_{3}$ (soybean) crops and conclude that variation in diffuse and direct light positively affects plant productivity in $\mathrm{C} 4$ crops. Since $\mathrm{C}_{3}$ crops become light-saturated more rapidly than $\mathrm{C}_{4}$ crops, they seem to not benefit from a change in light quantity and quality (i.e., more diffuse light, less direct light).

During midday hours, when plant productivity is not light-limited, high AOD conditions $(>0.4)$ enhance GPP by $\sim 13 \%$ at deciduous forests. On the other hand, we found that high diffuse light does not provide an advantage for croplands and grasslands when the sun is overhead; for these vegetation types, we estimate that high AOD conditions reduce GPP by $\sim 17 \%$ during midday hours. The opposite effect of the aerosol light scattering on forest vs. croplands and grasslands seems to be related to the different canopy architectures (Cheng et al., 2015) and should be accounted for in land-cover change studies, especially in landscapes where croplands and grasslands are replacing forests (Pires and Costa, 2013).

We used the new MODIS 3-km AOD product that, despite acknowledged limitations over urban sites, confirmed the potential to characterize pollution over rural sites. For future studies, the promising Multi-Angle Implementation of Atmospheric Correction (MAIAC) algorithm should be used since it provides aerosol retrievals at even finer $(1 \mathrm{~km})$ resolution; furthermore, MAIAC is able to detect small clouds and discriminate smoke from clouds (Lyapustin et al., 2012a,b; Chudnovsky et al., 2013). Our study took advantage of routine measurements of diffuse PAR at some AmeriFlux sites; therefore, we recommend 
that observations of diffuse PAR are extended to more FLUXNET sites together with LAI measurements at grassland sites.

\section{Author contribution} U. prepared the manuscript. X. Y. helped in the discussion and development of the study.

\section{Acknowledgments}

This project was supported in part by the facilities and staff of the Yale University Faculty of Arts and Sciences High Performance Computing Center. We thank the PI Brent Holben for his effort in establishing and maintaining the following AERONET sites: Bondville (co-PI: C. M. B. Lehmann), Harvard Forest, Howland, and Walker Branch. We also thank the AmeriFlux and FLUXNET community for the open use of FLUXNET data, as well as the PIs of Ameri-

Flux sites used for this research study: J. W. Munger (Harvard); D. Hollinger (Howland); A. Suyker (Mead); K. A. Novick (Morgan Monroe); K. Davis and A. Desai (Park Falls and Willow Creek); P. Curtis (UMBS). Scientists in charge of the UMBS site acknowledge their funding source: the U.S. Department of Energy's Office of Science, Office of Biological and Environmental Research, Ameriflux Management project under Flux Core Site agreement No. 7096915 through Lawrence Berkeley National Laboratory. We acknowledge the MODIS mission scientists and associated NASA personnel for the production of the data used in this research study.

\section{References}

Alton, P., North, P., Kaduk, J., Los, S., 2005. Radiative transfer modeling of direct and diffuse sunlight in a Siberian pine forest. J. Geophys. Res.-Atmos. 110 (D23). 
Alton, P. B., North, P. R., Los, S. O., 2007. The impact of diffuse sunlight on canopy light-use efficiency, gross photosynthetic product and net ecosystem exchange in three forest biomes. Global Change Biol. 13 (4), 776-787.

Artaxo, P., Rizzo, L. V., Brito, J. F., Barbosa, H. M. J., Arana, A., Sena, E. T., Cirino, G. G., Bastos, W., Martin, S. T., Andreae, M. O., 2013. Atmospheric aerosols in amazonia and land use change: from natural biogenic to biomass burning conditions. Faraday Discussions.

Baldocchi, D., 2008. "Breathing" of the terrestrial biosphere: lessons learned from a global network of carbon dioxide flux measurement systems. Aust. J. Bot. 56 (1), 1-26.

Baldocchi, D., Falge, E., Gu, L., Olson, R., Hollinger, D., Running, S., Anthoni, P., Bernhofer, C., Davis, K., Evans, R., Fuentes, J., Goldstein, A., Katul, G., Law, B., Lee, X., Malhi, Y., Meyers, T., Munger, W., Oechel, W., Paw, K. T., Pilegaard, K., Schmid, H. P., Valentini, R., Verma, S., Vesala, T., Wilson, K., Wofsyothers, S., 2001. FLUXNET: A new tool to study the temporal and spatial variability of ecosystem-scale carbon dioxide, water vapor, and energy flux densities. Bull. Amer. Meteor. Soc. 82 (11), 2415-2434.

Beer, C., Reichstein, M., Tomelleri, E., Ciais, P., Jung, M., Carvalhais, N., Rödenbeck, C., Arain, M. A., Baldocchi, D., Bonan, G. B., Bondeau, A., Cescatti, A., Lasslop, G., Lindroth, A., Lomas, M., Luyssaert, S., Margolis, H., Oleson, K. W., Roupsard, O., Veenendaal, E., Viovy, N., Williams, C., Woodward, F. I., Papale, D., 2010. Terrestrial gross carbon dioxide uptake: global distribution and covariation with climate. Science 329 (5993), 834-838.

Carlton, A. G., Pinder, R. W., Bhave, P. V., Pouliot, G. A., 2010. To what extent can biogenic SOA be controlled? Environ Sci. Technol. 44 (9), 33763380.

Cheng, S. J., Bohrer, G., Steiner, A. L., Hollinger, D. Y., Suyker, A. P., P., R. P., Nadelhoffer, K. J., 2015. Variations in the influence of diffuse light on 
gross primary productivity in temperate ecosystems. Agric. For. Meteorol. $201,98-110$

Chudnovsky, A. A., Kostinski, A., Lyapustin, A., Koutrakis, P., 2013. Spatial scales of pollution from variable resolution satellite imaging. Environ. Pollut. $172,131-138$.

Cirino, G. G., Souza, R. F., Adams, D. K., Artaxo, P., 2014. The effect of atmospheric aerosol particles and clouds on net ecosystem exchange in amazonia. Atmos. Chem. Phys. 14 (13), 6523-6543.

Foken, T., 2008. The energy balance closure problem: an overview. Ecol. Appl. 18 (6), 1351-1367.

Gitelson, A. A., Viña, A., Arkebauer, T. J., Rundquist, D. C., Keydan, G., Leavitt, B., 2003. Remote estimation of leaf area index and green leaf biomass in maize canopies. Geophys. Res Lett. 30 (5).

Greenwald, R. B., M. H., Xu, J., Cohan, D., Hoogenboom, G., Chameides, W. L., 2006. The influence of aerosols on crop production: A study using the ceres crop model. Agr. Syst. 89, 390-413.

Gu, L., Baldocchi, D., Verma, S. B., Black, T., Vesala, T., Falge, E. M., Dowty, P. R., 2002. Advantages of diffuse radiation for terrestrial ecosystem productivity. J. Geophys. Res. 107 (D6), 4050.

${ }_{645}$ Gu, L., Baldocchi, D. D., Wofsy, S. C., Munger, J. W., Michalsky, J. J., Urbanski, S. P., Boden, T. A., 2003. Response of a deciduous forest to the Mount Pinatubo eruption: Enhanced photosynthesis. Science 299 (5615), 2035-2038.

Hallquist, M., Wenger, J. C., Baltensperger, U., Rudich, Y., Simpson, D., Claeys, M., Dommen, J., Donahue, N. M., George, C., Goldstein, A. H., Hamilton, J. F., Herrmann, H., Hoffmann, T., Iinuma, Y., Jang, M., Jenkin, M. E., Jimenez, J. L., Kiendler-Scharr, A., Maenhaut, W., McFiggans, G., Mentel, T. F., Monod, A., Prévôt, A. S. H., Seinfeld, J. H., Surratt, J. D., 
Szmigielski, R., Wildt, J., 2009. The formation, properties and impact of secondary organic aerosol: current and emerging issues. Atmos. Chem. Phys. 9 (14), 5155-5236.

Hand, J. L., Schichtel, B. A., Malm, W. C., Pitchford, M. L., 2012. Particulate sulfate ion concentration and $\mathrm{SO}_{2}$ emission trends in the United States from the early 1990s through 2010. Atmos. Chem. Phys. 12 (21), 10353-10365.

Hollinger, D. Y., Kelliher, F. M., Byers, J. N., Hunt, J. E., McSeveny, T. M., Weir, P. L., 1994. Carbon dioxide exchange between an undisturbed oldgrowth temperate forest and the atmosphere. Ecology, 134-150.

Kanniah, K. D., Beringer, J., North, P., Hutley, L., 2012. Control of atmospheric particles on diffuse radiation and terrestrial plant productivity: A review. Prog. Phys. Geog. 36 (2), 209-237.

${ }_{665}$ Knohl, A., Baldocchi, D. D., 2008. Effects of diffuse radiation on canopy gas exchange processes in a forest ecosystem. J. Geophys. Res.-Biogeo. 113 (G2).

Letts, M. G., Lafleur, P. M., Roulet, N. T., 2005. On the relationship between cloudiness and net ecosystem carbon dioxide exchange in a peatland ecosystem. Ecoscience 12 (1), 53-59.

Levy, R. C., Mattoo, S., Munchak, L. A., Remer, L. A., Sayer, A. M., Hsu, N. C., 2013. The Collection 6 MODIS aerosol products over land and ocean. Atmos. Meas. Tech. 6, 2989-3034.

Levy, R. C., Remer, L. A., Kleidman, R. G., Mattoo, S., Ichoku, C., Kahn, R., Eck, T. F., 2010. Global evaluation of the Collection 5 MODIS dark-target aerosol products over land. Atmos. Chem. Phys. 10 (21), 10399-10420.

Lyapustin, A., Korkin, S., Wang, Y., Quayle, B., Laszlo, I., 2012a. Discrimination of biomass burning smoke and clouds in MAIAC algorithm. Atmos. Chem. Phys. 12 (20), 9679-9686. 
Lyapustin, A., Wang, Y., Laszlo, I., Korkin, S., 2012b. Improved cloud and snow screening in maiac aerosol retrievals using spectral and spatial analysis. Atmos. Meas. Tech. 5 (4), 843-850.

Matsui, T., Beltrán-Przekurat, A., Niyogi, D., Pielke, R. A., Coughenour, M., 2008. Aerosol light scattering effect on terrestrial plant productivity and energy fluxes over the eastern united states. J. Geophys. Res.-Atmos. 113 (D14).

Munchak, L. A., Levy, R. C., Mattoo, S., Remer, L. A., Holben, B. N., Schafer, J. S., Hostetler, C. A., Ferrare, R. A., 2013. MODIS $3 \mathrm{~km}$ aerosol product: applications over land in an urban/suburban region. Atmos. Meas. Tech. 6 (7), 1747-1759.

URL http://www . atmos-meas-tech.net/6/1747/2013/

${ }_{690}$ Niyogi, D., Chang, H.-I., Saxena, V. K., Holt, T., Alapaty, K., Booker, F., Chen, F., Davis, K. J., Holben, B., Matsui, T., Meyers, T., Oechel, W. C., Pielke, R. A., Wells, R., Wilson, K., Xue, Y., 2004. Direct observations of the effects of aerosol loading on net ecosystem $\mathrm{CO}_{2}$ exchanges over different landscapes. Geophys. Res Lett. 31 (20).

Oliveira, P. H. F., Artaxo, P., Pires, C., De Lucca, S., Procópio, A., Holben, B., Schafer, J., Cardoso, L. F., Wofsy, S. C., Rocha, H. R., 2007. The effects of biomass burning aerosols and clouds on the $\mathrm{CO}_{2}$ flux in amazonia. Tellus B 59 (3), 338-349.

Pires, G. F., Costa, M. H., 2013. Deforestation causes different subregional effects on the Amazon bioclimatic equilibrium. Geophys. Res Lett. 40 (14), $3618-3623$.

Ramanathan, V., Crutzen, P., Kiehl, J., Rosenfeld, D., 2001. Aerosols, climate, and the hydrological cycle. Science 294 (5549), 2119-2124.

Remer, L. A., Mattoo, S., Levy, R. C., Munchak, L. A., 2013. MODIS 3 km aerosol product: algorithm and global perspective. Atmos. Meas. Tech. 6 (1), 1829-1844. 
Rocha, A. V., Hong-Bing, S., Vogel, C. S., Peter, S. H., Curtis, P. S., 2004. Photosynthetic and water use efficiency responses to diffuse radiation by an aspen-dominated northern hardwood forest. Forest Sci. 50 (6), 793-801.

Roderick, M. L., Farquhar, G. D., Berry, S. L., Noble, I. R., 2001. On the direct effect of clouds and atmospheric particles on the productivity and structure of vegetation. Oecologia 129 (1), 21-30.

URL http://dx.doi.org/10.1007/s004420100760

Schaefer, K., Schwalm, C. R., Williams, C., Arain, M. A., Barr, A., Chen, J. M., 715 Davis, K. J., Dimitrov, D., Hilton, T. W., Hollinger, D. Y., Humphreys, E., Poulter, B., Raczka, B. M., Richardson, A. D., Sahoo, A., Thornton, P., Vargas, R., Verbeeck, H., Anderson, R., Baker, I., Black, T. A., Bolstad, P., Chen, J., Curtis, P. S., Desai, A. R., Dietze, M., Dragoni, D., Gough, C., Grant, R. F., Gu, L., Jain, A., Kucharik, C., Law, B., Liu, S., Lokipitiya, E., Margolis, H. A., Matamala, R., McCaughey, J. H., Monson, R., Munger, J. W., Oechel, W., Peng, C., Price, D. T., Ricciuto, D., Riley, W. J., Roulet, N., Tian, H., Tonitto, C., Torn, M., Weng, E., Zhou, X., 2012. A model-data comparison of gross primary productivity: Results from the North American Carbon Program site synthesis. J. Geophys. Res.-Biogeo. 117 (G3).

Steiner, A. L., Chameides, W. L., 2005. Aerosol-induced thermal effects increase modelled terrestrial photosynthesis and transpiration. Tellus B 57 (5), 404411.

Steiner, A. L., Mermelstein, D., Cheng, S. J., Twine, T. E., Oliphant, A., 2013. Observed impact of atmospheric aerosols on the surface energy budget. Earth Interact. 17 (14), 1-22.

Streets, D. G., Yan, F., Chin, M., Diehl, T., Mahowald, N., Schultz, M., Wild, M., Wu, Y., Yu, C., 2009. Anthropogenic and natural contributions to regional trends in aerosol optical depth, 1980-2006. J. Geophys. Res.-Atmos. 114 (D10). 
${ }_{735}$ Turner, D. P., Cohen, W. B., Kennedy, R. E., Fassnacht, K. S., Briggs, J. M., 1999. Relationships between leaf area index and Landsat ${ }^{\mathrm{TM}}$ spectral vegetation indices across three temperate zone sites. Remote Sens. Environ. 70 (1), $52-68$.

Wild, M., 2009. Global dimming and brightening: A review. J. Geophys. Res.740 Atmos. 114 (D10).

Wild, M., 2012. Enlightening global dimming and brightening. B. Am. Meteorol. Soc. 93 (1), 27-37.

Wild, M., Trüssel, B., Ohmura, A., Long, C. N., König-Langlo, G., Dutton, E. G., Tsvetkov, A., 2009. Global dimming and brightening: An update beyond 2000. J. Geophys. Res.-Atmos. 114 (D10).

Wohlfahrt, G., Hammerle, A., Haslwanter, A., Bahn, M., Tappeiner, U., Cernusca, A., 2008. Disentangling leaf area and environmental effects on the response of the net ecosystem $\mathrm{CO}_{2}$ exchange to diffuse radiation. Geophys. Res Lett. 35 (16). 


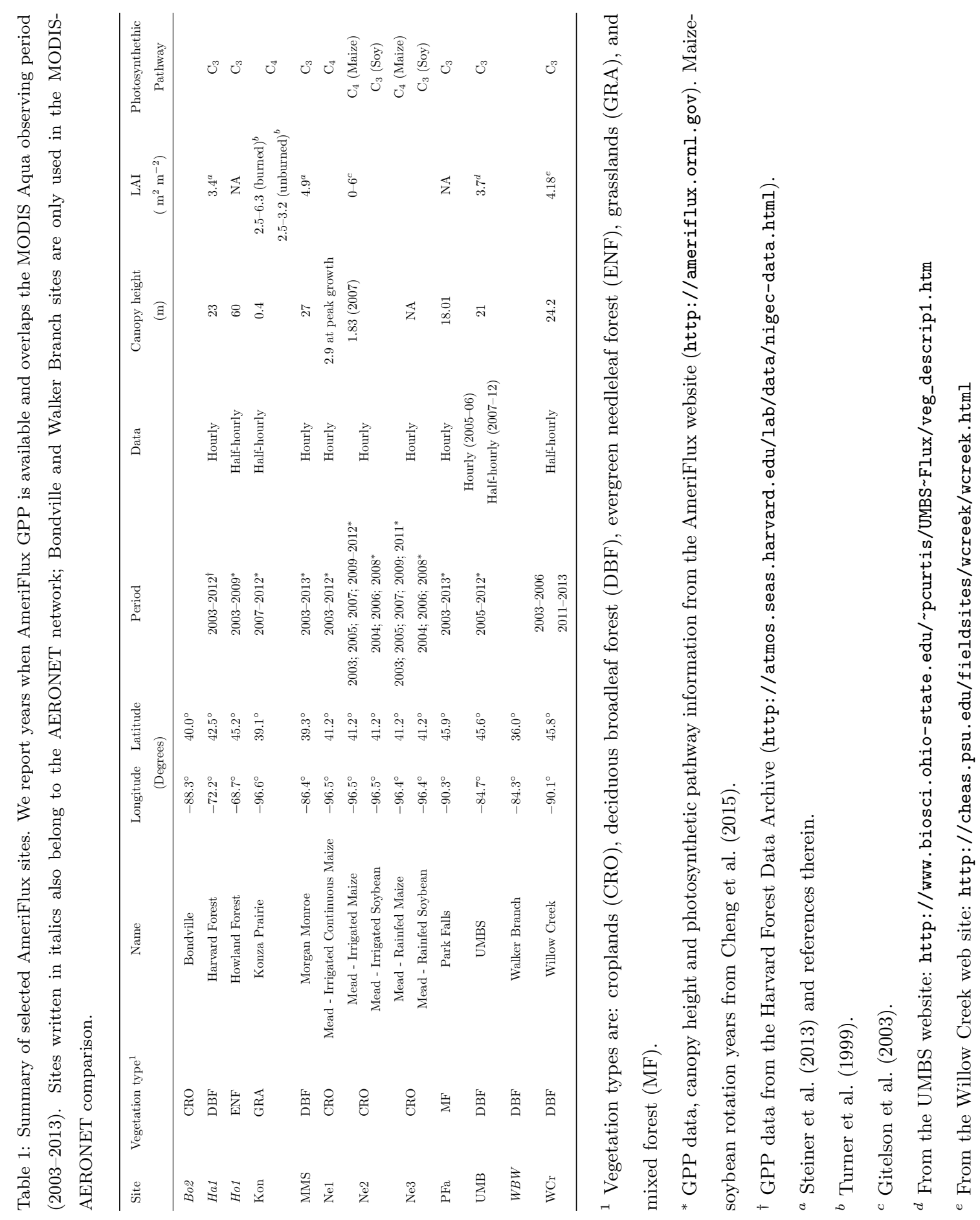


Table 2: Pearson's correlation coefficient $(R)$ computed between quasi-coincident AmeriFlux observations and instantenous MODIS Aqua 3-km AOD (10:00-14:00 Local Time). Correlation coefficients in bold are statistically significant based on a Pearson's test (95\% confidence interval).

\begin{tabular}{|c|c|c|c|c|c|}
\hline \multirow[t]{2}{*}{ Site } & \multirow[t]{2}{*}{ Vegetation type } & \multicolumn{4}{|c|}{ Pearson's $R$} \\
\hline & & $\mathrm{PAR}_{d i f}-\mathrm{AOD}$ & $\mathrm{PAR}_{d i r}-\mathrm{AOD}$ & $\mathrm{GPP}-P A R_{d i f}$ & GPP-AOD \\
\hline Ha1 & $\mathrm{DBF}$ & - & - & - & 0.136 \\
\hline Ho1 & ENF & 0.936 & -0.695 & 0.446 & 0.095 \\
\hline Kon & $\mathrm{DBF}$ & - & - & - & -0.074 \\
\hline MMS & $\mathrm{DBF}$ & 0.804 & -0.743 & 0.379 & 0.409 \\
\hline $\mathrm{Ne1-C} 4$ & CRO (Irr.) & 0.774 & -0.545 & -0.048 & 0.090 \\
\hline $\mathrm{Ne} 2-\mathrm{C}_{4}$ & CRO (Irr.) & 0.792 & -0.560 & -0.069 & 0.010 \\
\hline $\mathrm{Ne} 2-\mathrm{C}_{3}$ & CRO (Irr.) & 0.793 & -0.603 & -0.039 & -0.015 \\
\hline $\mathrm{Ne} 3-\mathrm{C}_{4}$ & CRO (Rain) & 0.779 & -0.660 & -0.095 & -0.152 \\
\hline $\mathrm{Ne} 3-\mathrm{C}_{3}$ & CRO (Rain) & 0.761 & -0.584 & -0.022 & 0.011 \\
\hline $\mathrm{PFa}$ & $\mathrm{MF}$ & - & - & - & 0.118 \\
\hline UMB & $\mathrm{DBF}$ & 0.753 & -0.297 & 0.233 & 0.005 \\
\hline $\mathrm{WCr}$ & DBF & - & - & - & 0.061 \\
\hline
\end{tabular}


Table 3: Multiple linear regression (MLR) standardized coefficients $(\beta)$ computed using quasicoincident AmeriFlux observations and MODIS Aqua 3-km AOD (10:00-14:00 Local Time). GPP is the dependent variable; surface atmospheric temperature (SAT), diffuse and direct PAR $\left(\mathrm{PAR}_{\text {dif }}\right.$ and $\left.\mathrm{PAR}_{\text {dir }}\right)$ and vapor pressure deficit (VPD) are the independent variable. Statistically significant standardized coefficients are reported in bold $(p$-val $<0.05)$.

\begin{tabular}{|c|c|c|c|c|c|c|}
\hline Site & Vegetation type & & SAT & $\mathrm{PAR}_{d i f}$ & $\mathrm{PAR}_{d i r}$ & VPD \\
\hline \multirow{2}{*}{ Ho1 } & \multirow{2}{*}{ ENF } & $\beta$ & -0.134 & 0.332 & 0.342 & -0.528 \\
\hline & & $p$-val & 0.5143 & 0.129 & 0.085 & 0.008 \\
\hline \multirow{2}{*}{ MMS } & \multirow{2}{*}{$\mathrm{DBF}$} & $\beta$ & 0.191 & 0.568 & 0.468 & -0.699 \\
\hline & & $p$-val & 0.118 & 0.021 & 0.055 & $5.35610^{-8}$ \\
\hline \multirow{2}{*}{$\mathrm{Ne}-\mathrm{C}_{4}$} & \multirow{2}{*}{ CRO (Irr.) } & $\beta$ & 0.702 & 0.185 & 0.364 & -0.690 \\
\hline & & $p$-val & $4.77010^{-18}$ & 0.025 & $1.68210^{-5}$ & $6.33110^{-18}$ \\
\hline \multirow{2}{*}{$\mathrm{Ne} 2-\mathrm{C}_{4}$} & \multirow{2}{*}{ CRO (Irr.) } & $\beta$ & 0.622 & 0.315 & 0.486 & -0.674 \\
\hline & & $p$-val & $4.31310^{-11}$ & 0.003 & $4.94510^{-6}$ & $1.93510^{-12}$ \\
\hline \multirow{2}{*}{$\mathrm{Ne} 2-\mathrm{C}_{3}$} & \multirow{2}{*}{ CRO (Irr.) } & $\beta$ & 0.405 & -0.639 & -0.552 & -0.638 \\
\hline & & $p$-val & 0.008 & 0.002 & 0.009 & $5.64510^{-5}$ \\
\hline \multirow{2}{*}{$\mathrm{Ne} 3-\mathrm{C}_{4}$} & \multirow{2}{*}{ CRO (Rain.) } & $\beta$ & 0.478 & 0.201 & 0.431 & -0.508 \\
\hline & & $p$-val & 0.002 & 0.218 & 0.009 & $6.42810^{-5}$ \\
\hline \multirow{2}{*}{$\mathrm{Ne} 3-\mathrm{C}_{3}$} & \multirow{2}{*}{ CRO (Rain.) } & $\beta$ & 0.428 & -0.541 & -0.507 & -0.680 \\
\hline & & $p$-val & $0.310^{-3}$ & $0.310^{-3}$ & $0.710^{-3}$ & $5.88110^{-8}$ \\
\hline
\end{tabular}


Table 4: Percentage change in midday average GPP (\% GPP, 10:00-14:00 Local Time) between high $(>0.4)$ and low $(<0.3)$ AOD days. Positive values indicate an increase in GPP under high AOD conditions. Percentage change in bold are statistically significant based on a Student's $t$ test with a $95 \%$ confidence interval.

\begin{tabular}{lcr}
\hline Site & Vegetation type & $\% \Delta$ GPP \\
\hline Ha1 & DBF & 8.127 \\
Ho1 & ENF & 7.304 \\
Kon & DBF & $\mathbf{- 1 9 . 9 9 5}$ \\
MMS & DBF & $\mathbf{1 3 . 8 2 4}$ \\
Ne1-C 4 & CRO (Irr.) & $\mathbf{- 1 4 . 5 3 7}$ \\
Ne2-C $_{4}$ & CRO (Irr.) & $\mathbf{- 1 1 . 2 9 5}$ \\
Ne2-C $_{3}$ & CRO (Irr.) & $-\mathbf{1 3 . 0 4 8}$ \\
Ne3-C $_{4}$ & CRO (Rain.) & $\mathbf{- 1 3 . 4 3 1}$ \\
Ne3-C 3 & CRO (Rain.) & $\mathbf{- 1 3 . 5 8 9}$ \\
PFa $_{\text {WCr }}$ & MF & 4.827 \\
& DBF & $\mathbf{1 2 . 5 7 6}$ \\
\hline
\end{tabular}




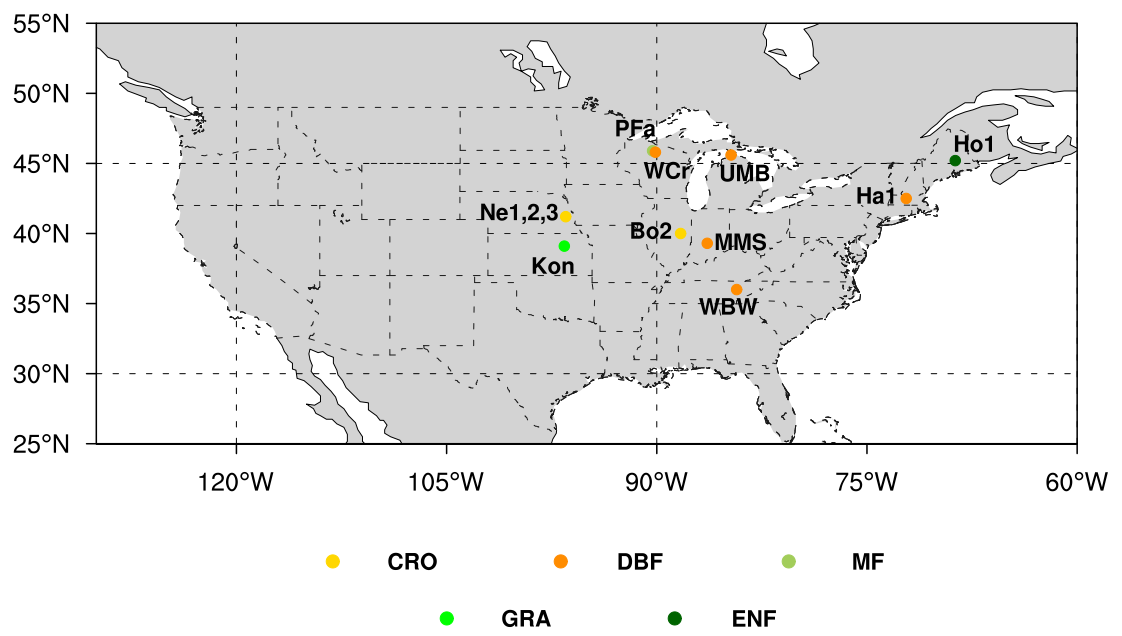

Figure 1: 

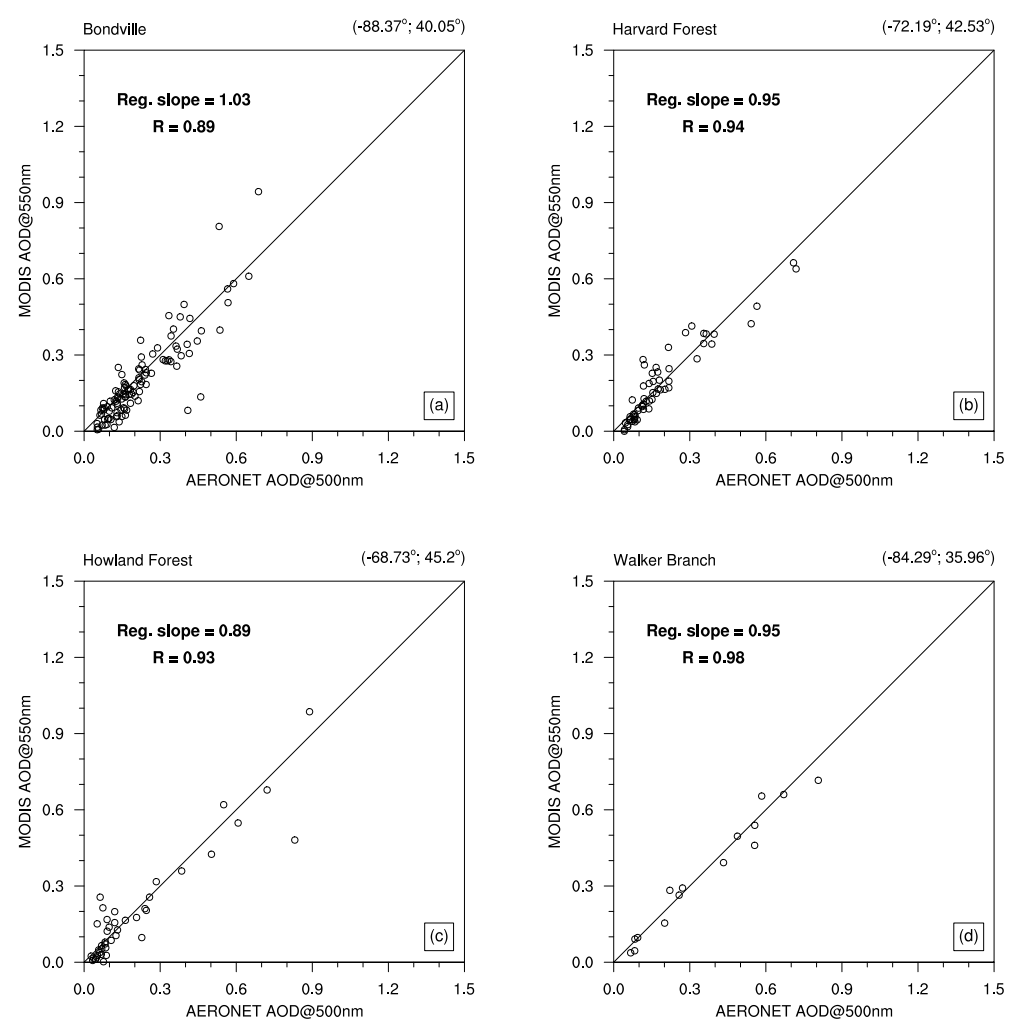

Figure 2: 

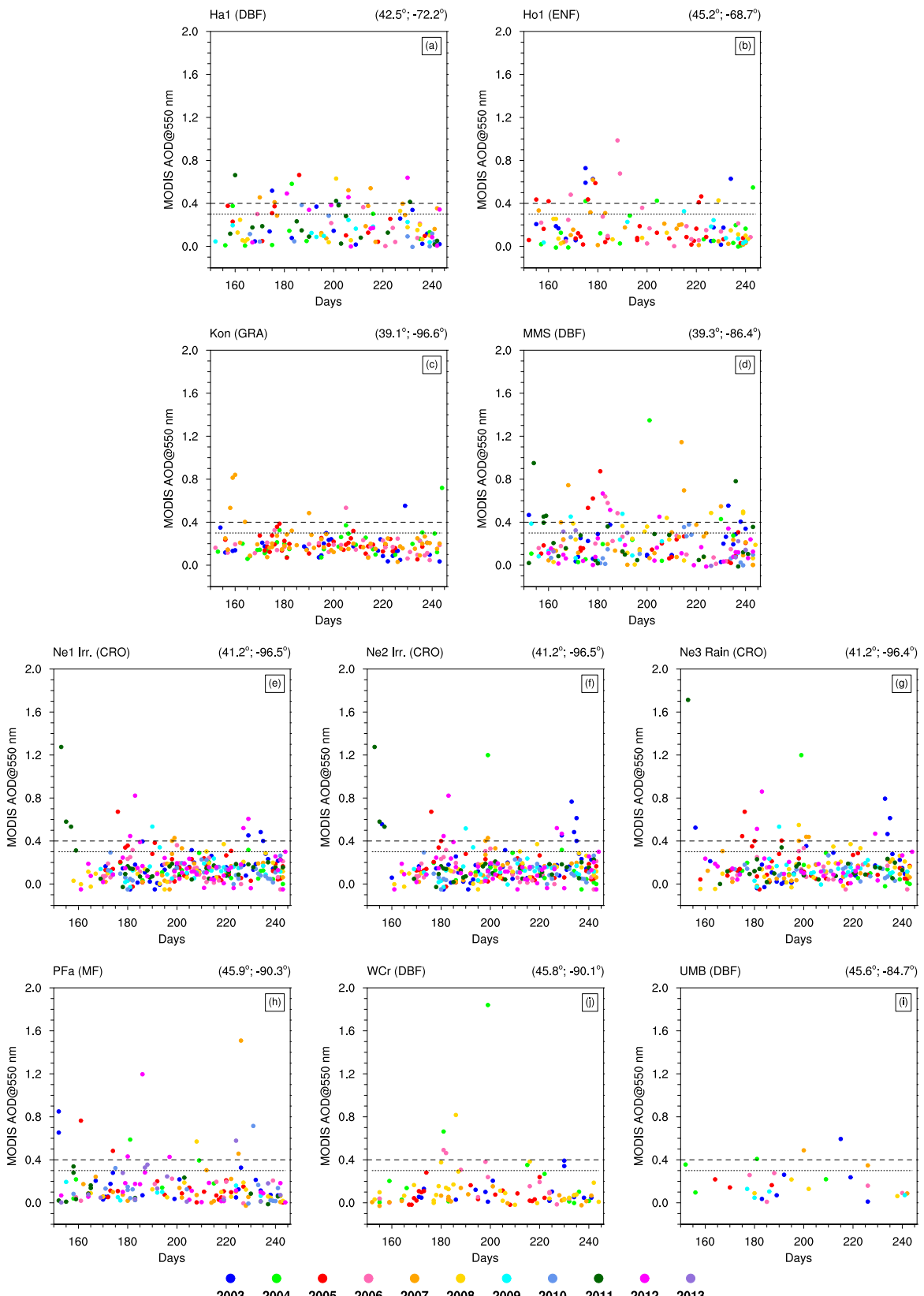

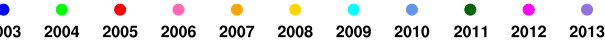

Figure 3: 

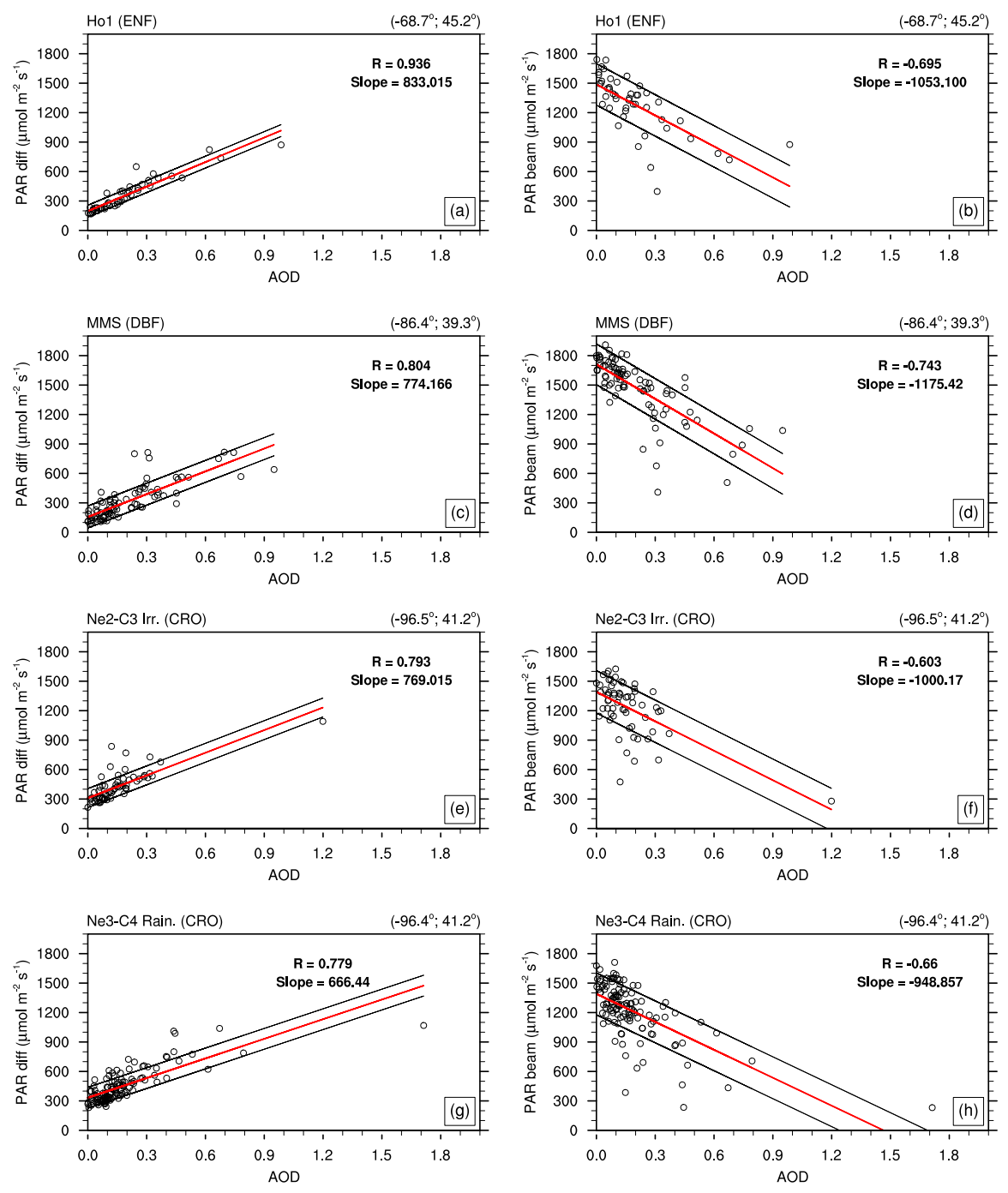

Figure 4: 

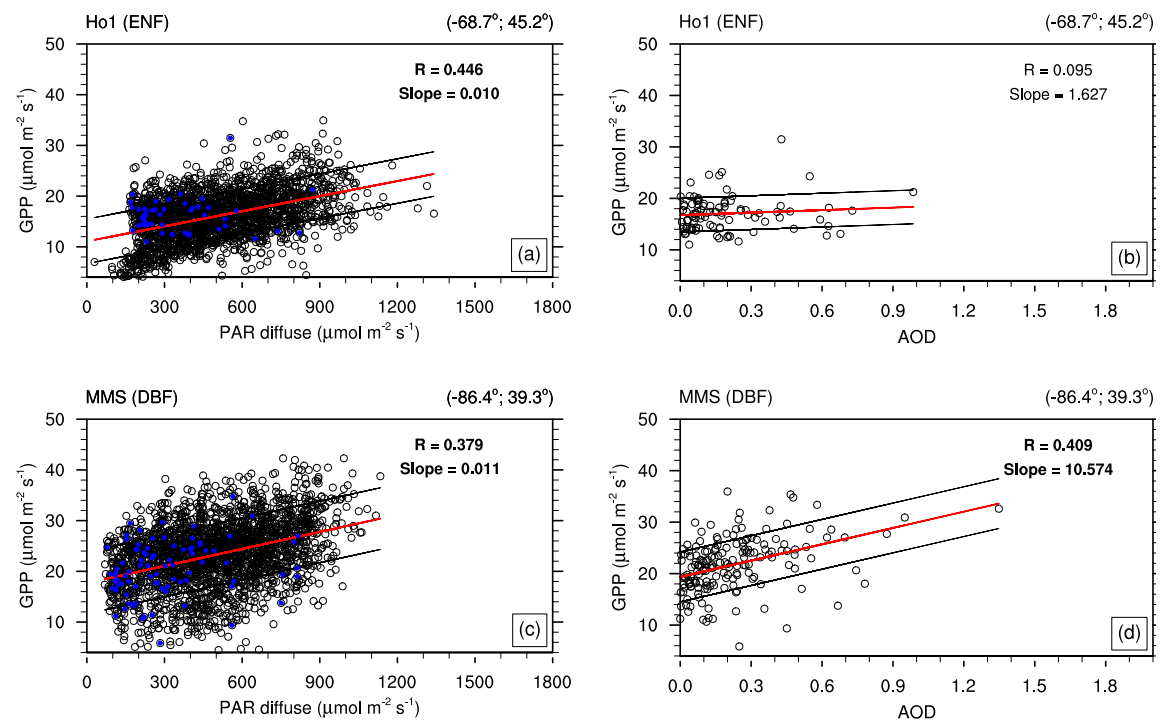

Figure 5: 

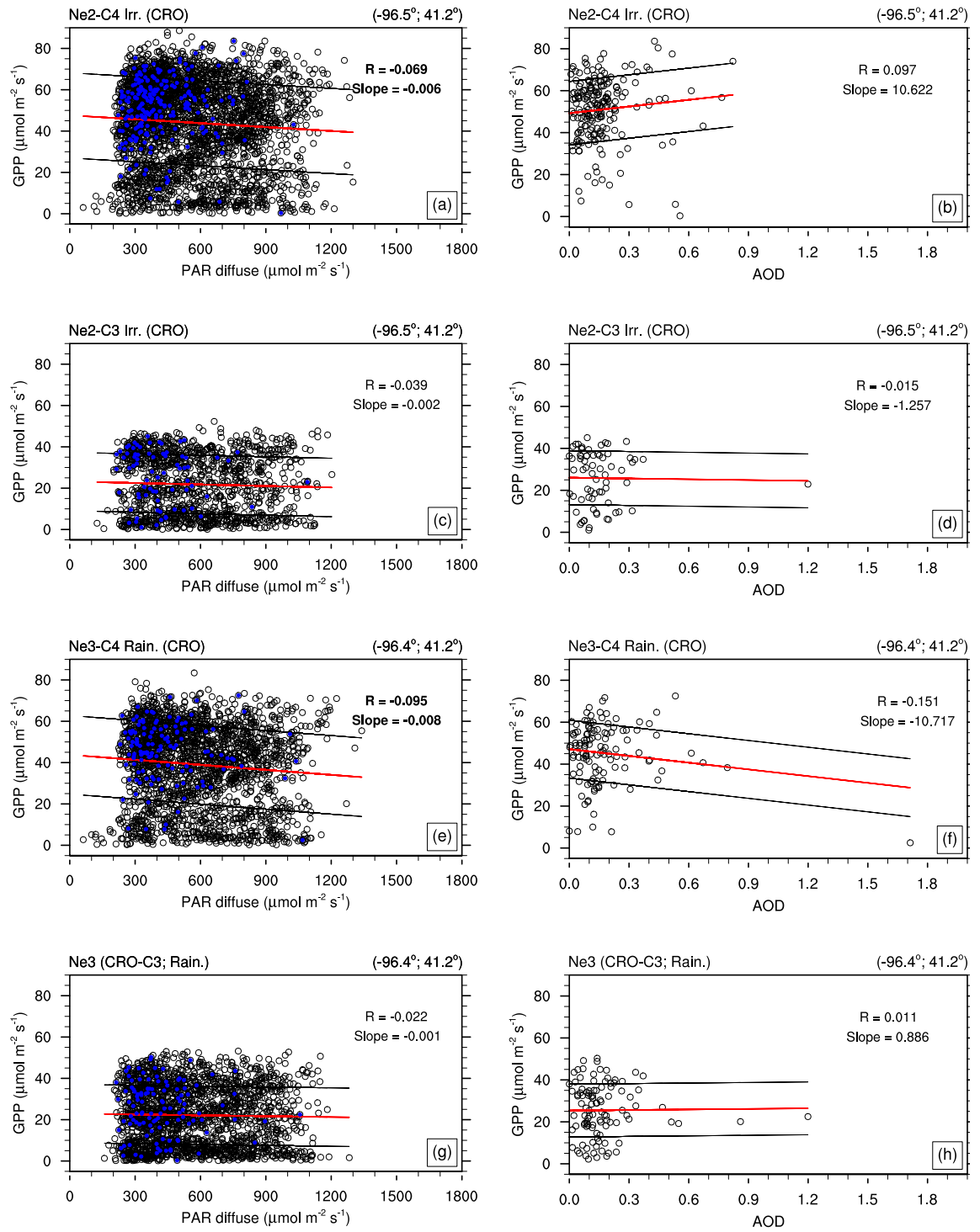

Figure 6: 

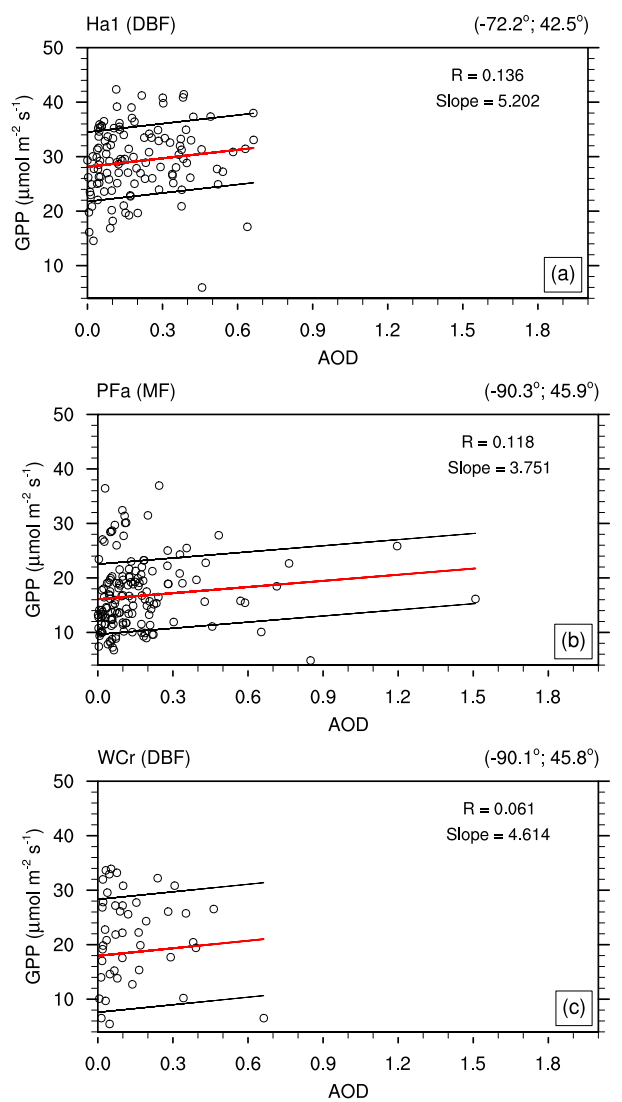

Figure 7: 

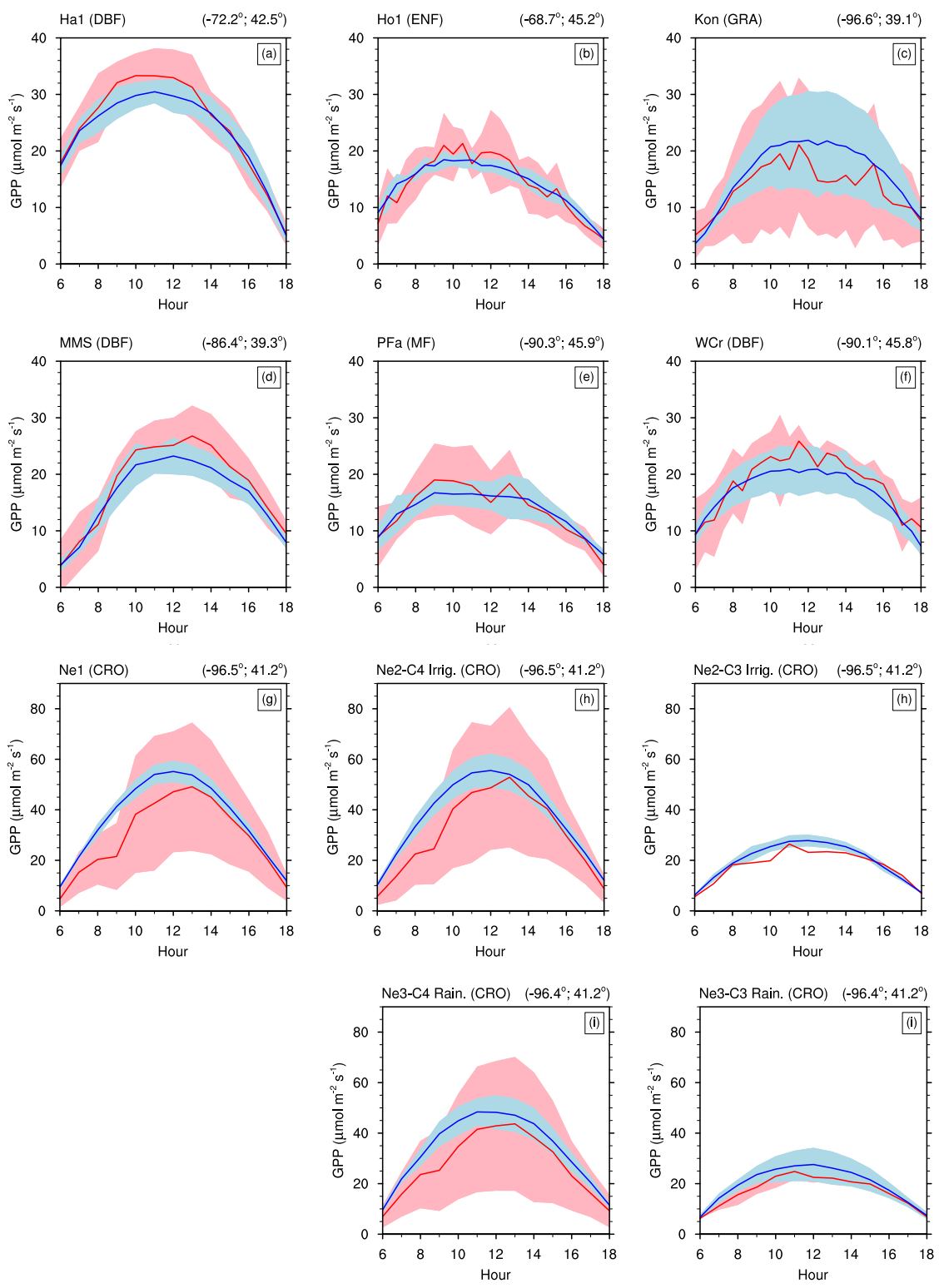

Figure 8: 
Figure 1: Selected AmeriFlux sites and respective vegetation types. Site information and vegetation type acronyms are gathered in Table 1. Bondville (Bo2) and Walker Branch (WBW) sites are only used in the MODIS-AERONET comparison.

Figure 2: MODIS Aqua 3-km AOD (at $550 \mathrm{~nm}$ ) compared to ground-based AERONET AOD (at $500 \mathrm{~nm}$ ) measurements available at four AmeriFlux sites during summer days (JuneAugust): (a) Bondville, [2003-06; 2008; 2010-13]; (b) Harvard Forest, [2007-13]; (c) Howland Forest, [2003-04; 2006-08]; and (d) Walker Branch, [2003-06; 2008]. For each site, the regression slope and correlation coefficient are indicated (all statistically significant at $95 \%$ confidence interval), and 1:1 line is plotted as a solid line.

Figure 3: MODIS Aqua 3-km AOD time series (summer days) at the selected AmeriFlux sites: (a) Harvard Forest, (b) Howland Forest, (c) Konza Prairie, (d) Morgan Monroe, (e) Mead Irrigated Maize, (f) Mead - Irrigated soybean-maize, (g) Mead - Rainfed soybean-maize, (h) Park Falls, (i) Willow Creek and (j) UMBS. Data show daily AOD average of instantaneous MODIS Aqua retrieval at $3 \mathrm{~km}$ resolution.

Figure 4: Relationship between quasi-coincident ground-based diffuse and direct PAR (both in $\mu \mathrm{mol} \mathrm{m}{ }^{-2} \mathrm{~s}^{-1}$ ) and MODIS AOD for all available years at the following AmeriFlux sites: (a-b) Howland Forest; (c-d) Morgan Monroe; (e-f) Mead - Irrigated maize $\left(\mathrm{C}_{4}\right)$; (g-h) Mead - Rainfed soybean $\left(\mathrm{C}_{3}\right)$. Data cover summer days (June-August). AmeriFlux diffuse/direct PAR are half-hourly/hourly observations collected between 10:00 and 14:00 LT. Instantaneous MODIS Aqua 3-km AOD are collected in a time span centered on AmeriFlux record time (30 minutes/one hour, depending on half-hourly/hourly data). For each plot: the red line indicates the regression line, black lines depict the 1- $\sigma$ interval; the regression slope and correlation coefficient are both included for each site (in bold if statistically significant at $95 \%$ confidence interval).

Figure 5: Relationship between GPP and MODIS AOD (left column) and GPP and diffuse PAR (right column) at the same AmeriFlux sites shown in Figure 4. Data cover summer days (June-August). AmeriFlux diffuse PAR and GPP (in $\mu \mathrm{mol} \mathrm{m} \mathrm{m}^{-2} \mathrm{~s}^{-1}$ ) are halfhourly/hourly observations (10-14:00 LT). Instantaneous MODIS Aqua 3-km AOD are selected in a time span centered on AmeriFlux record time (30 minutes/one hour, depending on half-hourly/hourly data). For each plot: the red line indicates the regression line, black lines depict the 1- $\sigma$ interval; the regression slope and correlation coefficient are both included for each site (in bold if statistically significant at $95 \%$ confidence interval). In plots on the left column, blue dots show instants when MODIS Aqua 3-km AODs overlap AmeriFlux data. 
Figure 6: As Figure 5 at the following AmeriFlux crop sites: (a-b) Mead - Irrigated maize $\left(\mathrm{C}_{4}\right)$; (c-d) Mead - Irrigated soybean $\left(\mathrm{C}_{3}\right)$; (e-f) Mead - Rainfed maize $\left(\mathrm{C}_{4}\right)$; and (g-h) Mead - Rainfed soybean $\left(\mathrm{C}_{3}\right)$.

Figure 7: Relationship between ground-based GPP $\left(\mu \mathrm{mol} \mathrm{m}{ }^{-2} \mathrm{~s}^{-1}\right)$ and MODIS AOD for all available years at the following sites: (a) Harvard Forest; (b) Park Falls; and (c) Willow Creek. Data cover summer days (June-August). AmeriFlux GPP estimates are halfhourly/hourly observations (10-14:00 LT). Instantaneous MODIS Aqua 3-km AOD are selected in a time span centered on AmeriFlux record time (30 minutes/one hour, depending on half-hourly/hourly data). For each plot: the red line indicates the regression line, black lines depict the 1- $\sigma$ interval; the regression slope and correlation coefficient are both included for each site (in bold if statistically significant at $95 \%$ confidence interval).

Figure 8: Average diurnal GPP cycle calculated at ten AmeriFlux sites under high (red line, AOD $>0.4)$ and low (blue line, AOD < 0.3) AOD days. Hourly/half-hourly GPP $\left(\mu \mathrm{mol} \mathrm{m}^{-2}\right.$ $\mathrm{s}^{-1}$ ) observed between 6:00 and 18:00 LT are used based on data availability. One standard deviation is displayed with light blue for low AOD and light red for high AOD. 